\section{Characterisation of an OCS-dependent severe asthma population treated with mepolizumab}

A subpopulation of patients with asthma treated with maximal inhaled treatments is unable to maintain asthma control and requires additional therapy with oral corticosteroids (OCS); a subset of this population continues to have frequent exacerbations. Alternate treatment options are needed as daily use of OCS is associated with significant systemic adverse effects that affect many body systems and have a direct association with the dose and duration of OCS use. We compared the population demographics, medical conditions and efficacy responses of the OCS-dependent group from the DREAM study of mepolizumab with the group not managed with daily OCS.

Trial Registration Number NCT01000506.
Mepolizumab, an anti-interleukin 5 monoclonal antibody under development for severe asthma, has been shown to reduce peripheral and sputum eosinophils. ${ }^{1}{ }^{2}$ Mepolizumab is hypothesised to work by reducing eosinophilic driven airway inflammation. Mepolizumab has previously been shown to be steroid sparing in a small study. ${ }^{1}$ The DREAM study (NCT01000506) reported that mepolizumab can reduce the exacerbation rate by $39-52 \%$ in a severe asthma population. ${ }^{2}$ Approximately a third of the subjects $(n=188)$ who participated in the DREAM study were using daily oral corticosteroids (OCS) at baseline in addition to using high dose inhaled corticosteroid and an additional controller to treat their asthma. This group reported an average duration of OCS use of 4.1 years, a mean OCS dose of $17 \mathrm{mg} /$ day and a median peripheral blood baseline eosinophil level of 280 cells $/ \mu \mathrm{L}$, which was similar to that for the non-OCS dependent subgroup $(290$ cells $/ \mu L)$ (table 1). Sputum eosinophils levels were also similar between the OCS-dependent and non-OCS dependent groups, although only measured in a subset of subjects. Consistent with a recent finding from Severe Asthma Research Program (SARP), the OCS group also had greater baseline airway inflammation, as assessed by median $\mathrm{FE}_{\mathrm{NO}}$ (table 1 ). ${ }^{3}$

Mean baseline ACQ scores indicated both subgroups were not controlled; the OCSgroup had a mean ACQ-6 score of 2.5 compared with $2.3(\mathrm{p}=0.077)$ for the non-OCS group (table 2). Despite being on maximal therapy, the OCS group had a lower baseline mean $\mathrm{FEV}_{1}$, and lower FVC, and $\mathrm{FEV}_{1} / \mathrm{FVC}$ ratio when compared with the non-OCS group (table 1). The majority of subjects (75\%) in the OCS group reported having three or more exacerbations in the year prior to the study compared with $44 \%$ of the non-OCS group; $49 \%$ of the OCS group had severe exacerbations that required asthmarelated hospitalisation(s), intubation, or were considered near-fatal asthma events (table 3).

Table 1 Characteristics of the non-OCS and OCS dependent subgroups

\begin{tabular}{|c|c|c|c|}
\hline Variables & Non-OCS dependent $(n=428)$ & OCS dependent $(n=188)$ & $\mathrm{p}$ Value \\
\hline Mean age, years (SD) & $47.6(11.72)$ & $51.0(9.81)$ & $<0.001^{*}$ \\
\hline Sex, female \% (n) & $65(279)$ & $57(108)$ & $0.067 \dagger$ \\
\hline Body mass index $\left(\mathrm{kg} / \mathrm{m}^{2}\right)(\mathrm{SD})$ & $28.4(6.05)$ & $28.5(5.74)$ & $0.875^{*}$ \\
\hline Race, white \% (n) & $89(380)$ & $89(167)$ & $0.228 \dagger$ \\
\hline \multicolumn{4}{|l|}{$\mathrm{FEV}_{1} \%$ predicted (SD) } \\
\hline Prebronchodilator & $60.7(14.58)$ & $57.3(18.35)$ & $0.014^{*}$ \\
\hline Postbronchodilator & $72.3(16.87)$ & $67.7(19.38)$ & $0.003^{*}$ \\
\hline \multicolumn{4}{|l|}{$\mathrm{FEV}_{1} \mathrm{~L}(\mathrm{SD})$} \\
\hline Prebronchodilator & $1.91(0.62)$ & $1.80(0.73)$ & $0.045^{*}$ \\
\hline Postbronchodilator & $2.28(0.72)$ & $2.12(0.79)$ & $0.014^{*}$ \\
\hline \multicolumn{4}{|l|}{ FVC L (SD) } \\
\hline Prebronchodilator & $3.03(0.92)$ & $2.89(1.00)$ & $0.076^{*}$ \\
\hline Postbronchodilator & $3.38(0.97)$ & $3.26(1.06)$ & 0.161 * \\
\hline \multicolumn{4}{|l|}{$\mathrm{FEV}_{1} / \mathrm{FVC}$ ratio (SD) } \\
\hline PreBronchodilator & $0.63(0.12)$ & $0.62(0.13)$ & $0.159^{*}$ \\
\hline PostBronchodilator & $0.68(0.13)$ & $0.66(0.18)$ & $0.079^{*}$ \\
\hline \multicolumn{4}{|l|}{ Reversibility } \\
\hline Mean \% reversibility (SD) & $24.1(19.74)$ & $26.1(25.82)$ & $0.282^{*}$ \\
\hline \multicolumn{4}{|l|}{ Inflammation characteristics } \\
\hline Median baseline $\mathrm{FE}_{\mathrm{NO}} \mathrm{ppb}(\mathrm{IQR})$ & $27.5(17-52)$ & $38(22-65)$ & $<0.001 \ddagger$ \\
\hline Median baseline sputum eosinophil count \% (IQR) $\delta$ & $\begin{array}{l}n=46 \\
11.25(2.75-30.75)\end{array}$ & $\begin{array}{l}n=40 \\
13.88(4.00-40.25)\end{array}$ & $0.436 \ddagger$ \\
\hline Median baseline peripheral blood eosinophil count, cells/ $\mu \mathrm{L}$ (IQR) & $290(150-510)$ & $280(130-510)$ & $0.372 \ddagger$ \\
\hline \multicolumn{4}{|l|}{ Inflammation criteria at study entry } \\
\hline Peripheral eosinophils $\geq 300$ cells/ $\mu \mathrm{L}$ in previous 12 months $\%$ (n) & $71(256 / 359)$ & $65(109 / 168)$ & $0.136 \dagger$ \\
\hline Peripheral eosinophils $\geq 150$ cells/ $\mu \mathrm{L}$ at baseline $\%$ ( $n$ ) & 77 (328) & 74 (139) & $0.471 \dagger$ \\
\hline Sputum eosinophils $\geq 3 \%$ in previous 12 months $\%$ ( $n$ ) & $41(36 / 88)$ & $61(28 / 46)$ & $0.028 \dagger$ \\
\hline $\mathrm{FE}_{\mathrm{No}} \geq 50 \mathrm{ppb}$ at baseline or in previous 12 months $\%$ (n) & $44(174 / 392)$ & $52(88 / 168)$ & $0.082 \dagger$ \\
\hline \multicolumn{4}{|l|}{ Patient-reported outcomes } \\
\hline Mean ACQ-6 score (SD) & $2.3(1.06)$ & $2.5(1.17)$ & $0.077^{*}$ \\
\hline Mean overall AQLQ (SD) & $4.2(1.17)$ & $4.2(1.24)$ & $0.993^{*}$ \\
\hline
\end{tabular}


Table 2 Exacerbation rate

\begin{tabular}{|c|c|c|c|c|}
\hline & \multicolumn{2}{|c|}{ Non-OCS dependent } & \multicolumn{2}{|c|}{ OCS dependent } \\
\hline & Placebo $(n=110)$ & Mepolizumab $(n=318)$ & Placebo $(n=45)$ & Mepolizumab $(n=143)$ \\
\hline Exacerbation rate/year & 1.90 & 1.07 & 3.12 & 1.54 \\
\hline Rate ratio $(95 \% \mathrm{Cl})$ & \multicolumn{2}{|c|}{$0.56(0.42$ to 0.76$)$} & \multicolumn{2}{|c|}{$0.49(0.35$ to 0.70$)$} \\
\hline Interaction $\mathrm{p}$ value & \multicolumn{4}{|c|}{0.503} \\
\hline
\end{tabular}

\section{Table 3 Exacerbation History and Related Healthcare Utilization Events}

\begin{tabular}{lcc}
\hline & $\begin{array}{l}\text { Non-OCS } \\
\text { dependent }\end{array}$ & $\begin{array}{c}\text { OCS } \\
\text { dependent }\end{array}$ \\
\hline \% population with history in the past 12 months of: & 55 & 25 \\
2 exacerbations & 44 & 75 \\
$>2$ exacerbations & 22 & 25 \\
Reporting 1 or more prior hospitalization for an exacerbation & 3 & 7 \\
Reporting prior intubation(s) for exacerbation & 8 & 17 \\
Reporting prior near fatal event for exacerbation & & \\
\hline *one subject in the non-OCS dependent population had reported only one exacerbation at baseline and was \\
considered a protocol violator.
\end{tabular}

Mepolizumab reduced the peripheral eosinophils within 4 weeks of treatment and the effect was maintained for the duration of the study and was effective at reducing the frequency of exacerbations in the non-OCS and OCS groups during the 52-week treatment period with a numerically greater reduction noted in the OCS group (table 2). ${ }^{2}$ This difference was not statistically different. Placebo treated subjects in the OCS group had the highest exacerbation rate during the study. These results demonstrate that despite daily OCS use the OCS group continues to have severe disease impairment with persistent eosinophils, airway inflammation, reduced lung function, and are also at high risk for future exacerbations. These clinical parameters were reflected by the poor control status and poor quality of life reported at baseline. The efficacy results demonstrate that mepolizumab treatment of a population using OCS daily was able to reduce peripheral eosinophils and exacerbation risk to a similar extent as a non-OCS dependent group.

\section{M Prazma, ${ }^{1} \mathrm{~S}$ Wenzel, ${ }^{2} \mathrm{~N}$ Barnes, ${ }^{3,4,5}$ J A Douglass, ${ }^{6}$ B F Hartley, ${ }^{7}$ H Ortega ${ }^{1}$}

${ }^{1}$ GlaxoSmithKline, Research Triangle Park, North Carolina, USA

${ }^{2}$ Division of Pulmonary, Allergy and Critical Care, Department of Medicine, University of Pittsburgh, Pittsburgh, Pennsylvania, USA

${ }^{3}$ Respiratory Medical Franchise, GSK, Uxbridge, UK

${ }^{4}$ The William Harvey Research Institute, Barts,

London, UK

${ }^{5}$ The London School of Medicine and Dentistry, London, UK ${ }^{6}$ Department of Allergy and Immunology, The Royal Parkville, Victoria, Australia

${ }^{7}$ GlaxoSmithKline, Uxbridge, UK

Correspondence to Dr Hector Ortega, GlaxoSmithKline, 5 Moore Drive, PO Box 3317.3A, Research Triangle Park, NC 27709-3398, USA; hector.g.ortega@gsk.com Melbourne Hospital and The University of Melbourne,
Contributors CMP and HO contributed to the conception and design of the work and in the acquisition, analysis, or interpretation of data. BFH, $S W, J A D$ and NB contributed to the analysis, or interpretation of data. All authors contributed towards drafting the research letter and revising it critically for important intellectual content and provided final approval of the version to be published and agreed to be accountable for all aspects of the work in ensuring that questions related to the accuracy or integrity of any part of the work are appropriately investigated and resolved.

Funding This study was funded by GlaxoSmithKline. Competing interests None.

\section{Patient consent Obtained.}

Ethics approval The data presented within was a global clinical trial and various independent Ethics committees and IRBs reviewed and approved prior to study initiation.

Provenance and peer review Not commissioned; internally peer reviewed.

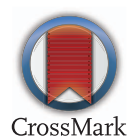

To cite Prazma CM, Wenzel S, Barnes $N$, et al. Thorax 2014;69:1141-1142.

Received 18 April 2014

Accepted 22 April 2014

Published Online First 16 May 2014

Thorax 2014;69:1141-1142.

doi:10.1136/thoraxjn-2014-205581

\section{REFERENCES}

1 Nair P, Pizzichini MM, Kjarsgaard M, et al. Mepolizumab for prednisone-dependent asthma with sputum eosinophilia. N Engl J Med 2009;360:985-93.

2 Pavord ID, Korn S, Howarth P, et al. Mepolizumab for severe eosinophilic asthma (DREAM): a multicentre, double-blind, placebo-controlled trial. Lancet 2012; 380:651-9.

3 Wysocki K, Park SY, Bleecker E, et al. Characterization of factors associated with systemic corticosteroid use in severe asthma: Data from the Severe Asthma Research Program. J Allergy Clin Immunol 2014;133:915-18. 